\title{
Phase II study of pemetrexed in combination with cisplatin in patients with advanced urothelial cancer: the PECULIAR study (KCSG 10-17)
}

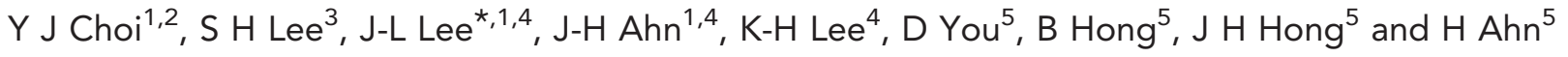 \\ ${ }^{1}$ Department of Oncology, Asan Medical Center, University of Ulsan College of Medicine, Seoul, Republic of Korea; ${ }^{2}$ Division of \\ Hemato-oncology, Department of Internal Medicine, Korea University Anam Hospital, Seoul, Republic of Korea; ${ }^{3}$ Department of \\ Internal Medicine, Seoul National University College of Medicine, Seoul, Republic of Korea; ${ }^{4}$ Department of Medicine, Asan \\ Medical Center, University of Ulsan College of Medicine, Seoul, Republic of Korea and ${ }^{5}$ Department of Urology, Asan Medical \\ Center, University of Ulsan College of Medicine, Seoul, Republic of Korea
}

\begin{abstract}
Background: Pemetrexed has shown a favourable response rate of about $30 \%$ with minimal toxicity when used as a single agent for treatment of advanced urothelial carcinoma. This phase II study evaluated the efficacy and safety of pemetrexed plus cisplatin in advanced urothelial carcinoma.
\end{abstract}

Methods: This multicentre, single-arm, open-label, phase II clinical trial enrolled patients who had advanced urothelial carcinoma, ECOG PS 0-2, and measurable disease. Pemetrexed $500 \mathrm{mg} \mathrm{m}^{-2}$ with cisplatin $70 \mathrm{mg} \mathrm{m}^{-2}$ on day 1 were administered every 3 weeks. The primary endpoint was the objective response rate (ORR). Secondary endpoints were progression-free survival (PFS), overall survival (OS), and toxicity.

Results: A total of 42 patients were enrolled (median age, 66 years; ECOG 0-1, 100\%; visceral metastasis, 54.8\%; recurrent disease, $57.1 \%)$. Twenty-seven partial responses for an ORR of $64.3 \%(95 \% \mathrm{Cl}, 49.2 \%-77.0 \%)$ were documented. Seven patients had stable disease. Median PFS and OS were $6.9(95 \% \mathrm{Cl}, 6.2-7.6)$ and $14.4(95 \% \mathrm{Cl}, 10.4-18.4)$ months, respectively. Grade 3 or 4 neutropenia was observed in $28.6 \%$ of patients. No patients experienced febrile neutropenia.

Conclusion: The combination of pemetrexed and cisplatin is active, and well tolerated in patients with advanced urothelial cancer as a first-line treatment.

Urothelial carcinoma is a common cancer that remains highly lethal if diagnosed at an advanced stage. Worldwide, it is estimated that there were 386300 new cases of bladder cancer in 2008, resulting in 150200 deaths (Jemal et al, 2011). The survival of patients with advanced urothelial carcinoma who receive best supportive care ranges from 4 to 6 months. The overall survival
(OS) has doubled with combination chemotherapy, and systemic chemotherapy is the most useful option in these patients. Cisplatin is thought to be the most effective chemotherapeutic agent, with a response rate of about 30\% (Rossof et al, 1979; Herr, 1980; De Lena et al, 1984). Cisplatin-based chemotherapy, such as methotrexate, vinblastine, adriamycin, and cisplatin and gemcitabine/cisplatin,

\footnotetext{
*Correspondence: Dr J-L Lee; E-mail: jaelyun@amc.seoul.kr

Presented in part at the Genitourinary Cancer Symposium, January 30th-February 1st, 2014, San Francisco, CA, USA, and at the 5th European Multidisciplinary Meeting on Urological Cancer, November 15th-17th, 2013, Marseille, France.
}

Received 4 August 2014; revised 7 October 2014; accepted 1 November 2014; published online 27 November 2014

(C) 2015 Cancer Research UK. All rights reserved 0007 - 0920/15 
continues to be the standard first-line treatment for advanced urothelial cancer, resulting in an objective response rate (ORR) of 45-60\%, a median progression-free survival (PFS) of 7-8 months, and a median OS of 14-15 months (von der Maase et al, 2000; Sternberg et al, 2006). Nevertheless, long-term survival is rare and haematologic toxicity is frequent. Thus, a more effective and safer therapy is required.

Pemetrexed is a potent inhibitor of thymidylate synthase (TS) (Taylor et al, 1992; Schultz et al, 1999) and other folate-dependent enzymes, including dihydrofolate reductase and glycinamide ribonucleotide formyltransferase (Shih et al, 1998). Pemetrexed has demonstrated a favourable response with minimal toxicity when used as a single agent in first-line and second-line treatment of advanced urothelial carcinoma. Response rates of $32 \%$ and $8-28 \%$ have been found for first-line and second-line settings, respectively (Paz-Ares et al, 2003a; Sweeney et al, 2006; Galsky et al, 2007). Excessive toxicity can largely be prevented by supplementation with low-dose folic acid and vitamin B12 (Sweeney et al, 2006). The combination of pemetrexed with cisplatin has already been attempted for various types of malignancies, demonstrating superior efficacy compared with gemcitabine plus cisplatin or cisplatin alone in patients with nonsquamous non-small-cell lung cancer (Scagliotti et al, 2008) and malignant pleural mesothelioma (Vogelzang et al, 2003). In addition, pemetrexed has an excellent safety profile and a convenient administration schedule. Therefore, this combination is now the standard regimen for first-line treatment of these malignancies.

This phase II trial was conducted to evaluate the efficacy and toxicity of the combination of pemetrexed with cisplatin in patients with advanced urothelial carcinoma.

\section{PATIENTS AND METHODS}

Study design and patients. This multicentre, single-arm, openlabel, phase II clinical trial evaluated the combination of pemetrexed and cisplatin in advanced urothelial carcinoma. To be enrolled, patients had to have a histologically confirmed diagnosis of urothelial (transitional cell) carcinoma, recurrent disease that was not amenable to local therapy or newly diagnosed distant metastatic disease, and a measurable disease defined by Response Evaluation Criteria in Solid Tumors (RECIST) 1.0 criteria. Patients had to be aged between 18 and 80 years, have an ECOG performance of $0-2$. Patients were also required to have adequate bone marrow, renal, and hepatic function, which was indicated by neutrophils $>3000 \mathrm{ul}^{-1}$, platelets $\geq 100000 \mathrm{ul}^{-1}$, and hemoglobin $>9 \mathrm{~g} \mathrm{dl}^{-1}$, serum creatinine $<1.5 \mathrm{mg} \mathrm{dl}^{-1}$ (if values were borderline, the creatinine clearance had to be $\geq 60 \mathrm{ml} \mathrm{min}^{-1}$ by Cockcroft and Gault formula), total bilirubin $\leq 1.5$ times the normal limit, and alanine aminotransferase and aspartate aminotransferase $\leq 3$ times the upper limit of normal. Exclusions were made for the micropapillary subtype of urothelial carcinoma, other tumour types such as adenocarcinoma or squamous cell carcinoma, the presence or history of CNS metastasis, prior palliative systemic chemotherapy or immunotherapy (but prior local intravesical chemotherapy or immunotherapy and adjuvant or neoadjuvant cisplatin-based chemotherapy 1 year or more before enrolment was allowed), the presence of second primary malignancy, a peripheral sensory neuropathy grade 2 or worse, and other serious illness or medical conditions. All patients were informed of the investigational nature of this study and gave written informed consent to participate. The protocol was approved by the institutional review boards of participating institutions and Korea Cancer Study Group (2008-0176/KCSG GU10-17) and registered at ClinicalTrials.gov (NCT01490437).
Treatment. Patients were treated with pemetrexed $500 \mathrm{mg} \mathrm{m}^{-2}$ for over $10 \mathrm{~min}$ and cisplatin $70 \mathrm{mg} \mathrm{m}^{-2}$ over $60 \mathrm{~min}$ intravenously on day 1 . All doses were based on actual body weight. Chemotherapy was repeated every 3 weeks for a maximum of eight cycles (unless there was earlier evidence of disease progression or intolerance of the study treatment). Patients received dexamethasone prophylaxis of $4 \mathrm{mg}$ orally twice per day on the day before, the day of, and the day after each day 1 treatment. All patients received oral folic acid (350-600 $\mu \mathrm{g})$ daily and a vitamin B12 injection $(1000 \mu \mathrm{g})$ every 9 weeks, beginning 1 week before the first dose and continuing until 3 weeks after the last dose of the study treatment.

Patients requiring a dose reduction of pemetrexed or cisplatin received the reduced dose for the remainder of the study. Patients who had two dose reductions and who experienced toxicity requiring a third dose reduction were discontinued from the study therapy. Cycle delays of up to 42 days were permitted for recovery from adverse events. Concomitant supportive therapies, such as granulocyte colony-stimulating factors or darbepoetin, were allowed.

Data evaluation and analyses. For efficacy, imaging using a contrast-enhanced CT scan or MRI scan was obtained at baseline, within 3 weeks before the start of treatment. Subsequently, the same imaging test was repeated every 6 weeks for response assessment. Response on imaging was determined by RECIST 1.0 criteria. For the first cycle, a complete blood count was done every week. Thereafter, treatment toxic effects including laboratory abnormalities were evaluated at each visit, using Common Terminology Criteria for Adverse Events (CTCAE) version 3.0. The primary endpoint of the study was the ORR, defined as the proportion of patients showing complete response or partial response.

The study used Simon's two-stage design to test the null hypothesis that the ORR was $\leq 30 \%$ against the alternative hypothesis that it was at least $50 \%$ at the one-sided 0.05 significance level with a power of 0.80 . During stage 1,19 eligible patients would be accrued. If there were six or fewer patients who showed a response, the study would be stopped. Otherwise, the study would continue to the second stage of accrual, for a total of 39 evaluable patients. With a $10 \%$ dropout rate, 44 patients were enrolled to ensure 39 evaluable patients. Secondary end points included PFS, OS, and toxicity. All survival analyses were performed using the Kaplan-Meier method. Statistical analyses were performed using PASW statistics version 18 (IBM Co., Armonk, NY, USA).

\section{RESULTS}

Patient characteristics. Between July 2009 and June 2013, a total of 44 patients with advanced urothelial carcinoma were recruited from two cancer centres in Korea. Two patients were ineligible because of a different histology and concomitant malignancy and excluded from the analyses. A total of 42 patients enrolled in this study were assessable for safety analysis. Of these 42 cases, 41 were assessable for efficacy analysis per protocol. One patient failed to undergo post-baseline tumour assessment because of clinical deterioration during cycle 1 with the response status unknown. This patient was counted as an early progressor and as such, all of the 42 treated patients are included in the intent-to-treat analysis. At the time of analysis, $57.1 \%$ of the patients (24 of 42 ) had died. Baseline characteristics are presented in Table 1. Of note, patients were predominantly male with a median age of 66 years (range, $42-78$ years) and all patients had good ECOG PS (0-1). Moreover, more than half of patients had visceral metastatic disease; especially, liver and bone metastases were observed in 
Table 1. Baseline characteristics $(n=42)$

\begin{tabular}{|c|c|}
\hline Characteristics & $n(\%)$ \\
\hline \multicolumn{2}{|l|}{ Age } \\
\hline Median (range) & $66.0(42-78)$ \\
\hline \multicolumn{2}{|l|}{ Gender } \\
\hline Female & $14(33.3)$ \\
\hline Male & $28(66.7)$ \\
\hline \multicolumn{2}{|c|}{ ECOG performance status } \\
\hline 0 & $3(7.1)$ \\
\hline 1 & $39(92.9)$ \\
\hline \multicolumn{2}{|l|}{ Primary site } \\
\hline Bladder & $23(54.8)$ \\
\hline Ureter & $11(26.2)$ \\
\hline Renal pelvis & $8(19.0)$ \\
\hline \multicolumn{2}{|l|}{ Disease status } \\
\hline Metastatic & $18(42.9)$ \\
\hline Recurrent & $24(57.1)$ \\
\hline \multicolumn{2}{|l|}{ Visceral metastasis } \\
\hline Yes & $25(59.5)$ \\
\hline \multicolumn{2}{|l|}{ Metastatic sites } \\
\hline Liver & $9(21.4)$ \\
\hline Lung & $20(47.6)$ \\
\hline Bone & $9(21.4)$ \\
\hline \multicolumn{2}{|l|}{ Bajorin risk group } \\
\hline Intermediate & $25(59.5)$ \\
\hline Low & $17(40.5)$ \\
\hline \multicolumn{2}{|l|}{ Prior therapy } \\
\hline None & $35(83.3)$ \\
\hline Adjuvant/neoadjuvant & $7(16.7)$ \\
\hline
\end{tabular}

$21.4 \%$ of patients. Seven patients had a history of platinum-based adjuvant/neoadjuvant chemotherapy.

Efficacy. No patients experienced complete response, 27 patients (64.3\%) experienced partial response, seven patients $(16.7 \%)$ had stable disease, eight patients $(19.0 \%)$ had progressive disease, and one patient $(2.4 \%)$ had unknown response data due to clinical deterioration during cycle 1 . The ORR was $64.3 \%$ (95\% CI, $49.2 \%-$ $77.0 \%$ ), and the disease control rate (complete response + partial response + stable disease) was $81.0 \%$. With a median follow-up duration of 14.3 months by the reverse Kaplan-Meier method (Schemper and Smith, 1996), the median PFS was 6.9 (95\% CI, 6.2-7.6) months and the median OS was 14.4 (95\% CI, 10.4-18.4) months (Figure 1).

Treatment administration and toxicity. The 42 enrolled patients received a total of 266 cycles of treatment. The median number of cycles administered was eight (range, 1-8). In our current study series, $3 \%$ of the cycles ( 8 of 266) had doses that were reduced: five because of nephrotoxicity and one each because of hepatotoxicity, hypersensitivity, or infection. In addition, $12.8 \%$ of cycles (35 of 266) were delayed, 33 because of haematologic toxicity. The mean dose intensities of pemetrexed and cisplatin were $94.9 \%$ $\left(158.2 \mathrm{mg} \mathrm{m}^{-2}\right.$ of $\left.166.7 \mathrm{mg} \mathrm{m}^{-2}\right)$ and $94.9 \%\left(22.1 \mathrm{mg} \mathrm{m}^{-2}\right.$ of $23.3 \mathrm{mg} \mathrm{m}^{-2}$ ) of the planned weekly doses, respectively.

All treated patients were assessable for toxicity. Laboratory, including haematologic, and non-laboratory toxicities are summarized in Table 2. There were no deaths attributed to protocol treatment. Grade 3/4 neutropenia (28.6\%) was the most common haematologic toxicity. Nonhaematologic laboratory toxicities were uncommon. There were two instances of grade 3 hepatotoxicity and one instance of grade 3 nephrotoxicity. Grade 4 nonlaboratory toxicity, a thromboembolic event, was observed in 1 of 42 patients. Grade 3 non-laboratory toxicity was reported in 7 of
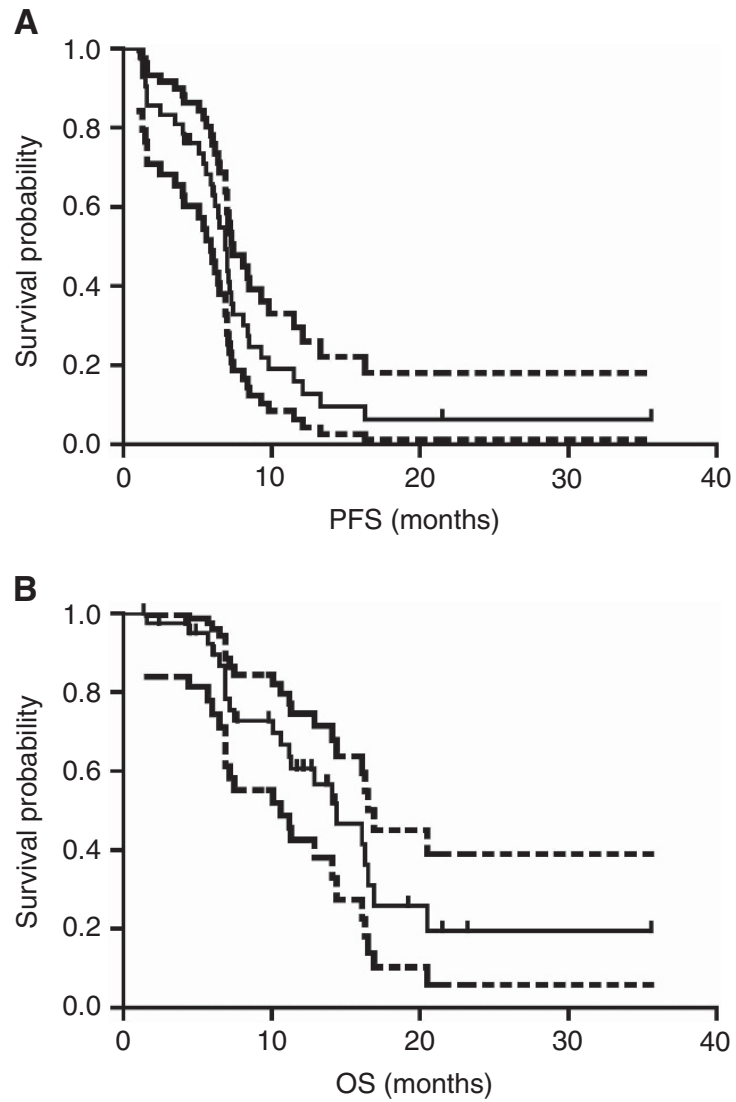

Figure 1. (A) Progression-free survival (PFS); (B) overall survival (OS). Dashed lines are the upper bound and lower bound of $95 \% \mathrm{Cl}$ of Kaplan-Meier estimates.

\section{Table 2. Adverse events $(n=42)$}

\begin{tabular}{|l|c|c|c|}
\hline Toxicities & $\begin{array}{c}\text { All grade, } \\
\mathbf{n}(\%)\end{array}$ & $\begin{array}{c}\text { Grade 3, } \\
\mathbf{n}(\%)\end{array}$ & $\begin{array}{c}\text { Grade 4, } \\
\mathbf{n}(\%)\end{array}$ \\
\hline Laboratory & $26(61.9)$ & $10(23.8)$ & $2(4.8)$ \\
\hline Neutropenia & $23(54.8)$ & $2(4.8)$ & 0 \\
Anaemia & $5(11.9)$ & $2(4.8)$ & 0 \\
Thrombocytopenia & $4(9.5)$ & $2(4.8)$ & 0 \\
AST/ALT elevation & $6(14.3)$ & $1(2.4)$ & 0 \\
Creatinine elevation & $25(59.5)$ & $1(2.4)$ & 0 \\
\hline Non-laboratory & $24(57.1)$ & $1(2.4)$ & 0 \\
\hline Nausea & $12(28.6)$ & 0 & 0 \\
Anorexia & $7(16.7)$ & 0 & 0 \\
Constipation & $36(85.7)$ & $1(2.4)$ & 0 \\
Mucositis & $6(14.3)$ & 0 & 0 \\
Fatigue & $7(16.7)$ & $1(2.4)$ & 0 \\
Myalgia & $6(14.3)$ & $2(4.8)$ & 0 \\
Oedema & $2(4.8)$ & $1(2.4)$ & $1(2.4)$ \\
Infection & \multicolumn{3}{|l|}{} \\
Thromboembolic event & Abbreviations: ALT = alanine aminotransferase; AST = aspartate aminotransferase. \\
\hline \multicolumn{4}{|l|}{}
\end{tabular}

42 patients including nausea, anorexia, fatigue, oedema, infection, and a thromboembolic event.

\section{DISCUSSION}

This current phase II trial demonstrated the ability of pemetrexed in combination with cisplatin to induce an ORR of $64.3 \%$ with a favourable toxicity profile in patients with advanced urothelial carcinoma. 
Pemetrexed has undergone evaluation as a single agent in a phase II study for first-line and second-line treatment. In the firstline setting, 9 out of 28 evaluable patients achieved a partial response $(32 \%, 95 \% \mathrm{CI}, 16 \%-52 \%)$ with a disease control rate of $68 \%$. The median response duration was 8.0 months and median overall survival was 9.4 months, which compare favourably with most single agents in this setting (Paz-Ares et al, 2003b). In the second-line setting, the response rate was $28 \%$ and median overall survival was 9.6 months (Sweeney et al, 2006). The safety was promising after vitamin supplementation; grade 3-4 haematologic toxicities were reported in less than $9 \%$ of patients and severe nonhaematologic toxicities developed in only one or two patients (Sweeney et al, 2006). However, another phase II trial in the second-line setting showed disparate results; the response rate was $8 \%$ failing to meet criteria for expanse after stage 1 and the febrile neutropenia developed in $15 \%$ of patients despite of vitamin supplementation (Galsky et al, 2007).

Pemetrexed in combination with gemcitabine was evaluated in phase II trials in advanced urothelial carcinoma. In European trial, gemcitabine $1250 \mathrm{mg} \mathrm{m}^{-2}$ was administered on day 1 and day 8 of each 21-day cycle, and pemetrexed $500 \mathrm{mg} \mathrm{m}^{-2}$ was given on day $8,90 \mathrm{~min}$ after the gemcitabine administration (von der Maase et al, 2006). E4802 trial adopted the concept of sequencedependent effect of pemetrexed, so on day 1, pemetrexed was administered first and followed $60 \mathrm{~min}$ later by gemcitabine $1000 \mathrm{mg} \mathrm{m}^{-2}$, different from the European trial, on day 1 and day 8 (Dreicer et al, 2008). However, both combination regimens showed moderate antitumour activity; the response rates were $28 \%$ and $32 \%$, respectively, with a median overall survival of 8 months and 13.4 months, respectively, while accompanied by significant haematologic toxicities (grade 3-4 neutropenia in 38\% and $75 \%$, respectively) and febrile neutropenia ( $17 \%$ and $11 \%$, respectively) (von der Maase et al, 2006; Dreicer et al, 2008). This non-platinum combination has not been pursed since thereafter, so the role of pemetrexed, especially in chemotherapy-naïve patients with urothelial carcinoma remains to be defined.

The combination of pemetrexed with cisplatin has already been evaluated in various types of malignancies. It demonstrated superior efficacy compared with cisplatin alone in malignant pleural mesothelioma (Vogelzang et al, 2003) and gemcitabine plus cisplatin combination in patients with nonsquamous non-smallcell lung cancer (Scagliotti et al, 2008). However, there was no published article on the efficacy and safety of pemetrexed combined with cisplatin in advanced urothelial carcinoma. Recently, results of phase I/II trial of biweekly pemetrexed $\left(400 \mathrm{mg} \mathrm{m}^{-2}\right)$ and cisplatin $\left(50 \mathrm{mg} \mathrm{m}^{-2}\right)$ were reported in an abstract; ORR was 39.5\% (15/38, 95\% CI, 24.0\%-56.6\%) and a median PFS was 6.7 months with a median OS of 10.5 months. Biweekly combination regimen also showed that favourable toxicities with the most frequent grade 3-4 toxicities were limited to neutropenia (13\%) and asthenia (5\%) (Martin et al, 2013).

In the current study, the ORR of $64 \%$ and disease control rate of $81 \%$ is encouraging, particularly because patients with visceral metastasis comprised more than half of the patients enrolled. The median PFS was 6.9 months and the median OS was 14.4 months. Actually, the ORR, PFS, and OS in the current study overlaps a large number of other combination regimens reported in phase II and phase III trials (Vaughn et al, 1998; Dimopoulos et al, 1999; Bellmunt et al, 2000; von der Maase et al, 2000; Sternberg et al, 2001). Considering promising results of combination chemotherapy in phase II trials (Vaughn et al, 1998; Dimopoulos et al, 1999; Bellmunt et al, 2000), which failed to show superior outcome in phase III trials (Bamias et al, 2004; Dreicer et al, 2004; Bellmunt et al, 2012), caution should be taken when interpreting our phase II result and further comparative studies are needed in the future.

As expected, pemetrexed plus cisplatin combination chemotherapy was well tolerated in patients advanced urothelial carcinoma.
The main toxicities of this regimen were haematologic, grade 3 or worse neutropenia in $29 \%$ of patients, but it did not lead to febrile neutropenia. Grade 3 or 4 non-laboratory toxicities were rare as these were observed in less than $5 \%$ of patients. The favourable toxicity observed in the current study is comparable with that observed in phase III study which compared pemetrexed plus cisplatin with gemcitabine plus cisplatin in non-small-cell lung cancer (Scagliotti et al, 2008). In that study, grade 3-4 neutropenia developed in $15 \%$, anaemia in $6 \%$, and thrombocytopenia in $4 \%$, and febrile neutropenia occurred in only $1 \%$ in the pemetrexed plus cisplatin arm, which were significantly lower compared with gemcitabine plus cisplatin group. In our study, grade 3-4 neutropenia seems to be higher in frequency and it may be caused by the longer treatment duration, eight cycles rather than six cycles.

The excellent tolerability of this regimen allowed higher dose density of cisplatin $\left(23.3 \mathrm{mg} \mathrm{m}^{-2} /\right.$ week $)$ and more treatment cycles comparing with other cisplatin-based regimens $\left(17.5 \mathrm{mg} \mathrm{m}^{-2}\right.$ per week and 4-6 cycles of methotrexate, vinblastine, adriamycin, and cisplatin or gemcitabine/cisplatin) (von der Maase et al, 2000; Sternberg et al, 2006). Relatively higher dose density of cisplatin might contribute to better outcomes of the current regimen. Further studies to determine adequate dose intensity and treatment cycle numbers are needed in the future.

The convenience of the pemetrexed and cisplatin is of note. It does not require mid-cycle visit for chemotherapy and it requires less transfusion and supportive cares such as erythropoietin or granulocyte colony-stimulating factor than did patients on the gemcitabine plus cisplatin (Scagliotti et al, 2008). Although patients need vitamin B12 injection every 9 weeks and daily medication of folic acid, detailed patient education on the importance of vitamin supplementation and close monitoring could secure patient compliance. Furthermore, considering very favourable toxicity profile, this regimen might be served as a platform for additional combination of target agents in the future.

It would be of great importance to identify biomarkers for the prediction of the sensitivity of the tumour to pemetrexed. Among potential biomarkers, TS, a main target of pemetrexed, and folylpolyglutamate synthetase, the enzyme responsible for activation of pemetrexed to its pharmacologically active form, have been shown to be promising predictors for various malignancies, especially in lung cancer and malignant mesothelioma (Takezawa et al, 2011; Christoph et al, 2012; Smit et al, 2012). Recently, a meta-analysis demonstrated that the response and clinical outcomes of patients with non-small-cell lung cancer treated by pemetrexed are better in those with a lower level of TS expression (Liu et al, 2013). Similarly, potential biomarkers should be evaluated in the future studies of pemetrexed in urothelial cancer to increase the success rate through enrichment and to individualize urothelial cancer treatment.

In conclusion, the combination of pemetrexed plus cisplatin combination given every 3 weeks is active and well tolerated in patients with advanced urothelial carcinoma in the first-line setting, and this regimen deserves further investigation.

\section{ACKNOWLEDGEMENTS}

We thank the patients and their families who took part in this study, the coordinators, and the investigators. We also thank Lilly Korea Co. for their kind donation of pemetrexed (Alimta ${ }^{\circledR}$ ) for this study. This study was supported in part by a grant (HI12C17880300, HI14C1931) from the Korean Health Technology R\&D Project, Ministry of Health and Welfare, Republic of Korea.

Trials Registration: The trial was registered with the National Cancer Institute (www.clinicaltrials.gov identifier NCT01490437). 


\section{CONFLICT OF INTEREST}

The authors have declared no conflict of interest.

\section{REFERENCES}

Bamias A, Aravantinos G, Deliveliotis C, Bafaloukos D, Kalofonos C, Xiros N, Zervas A, Mitropoulos D, Samantas E, Pectasides D, Papakostas P, Gika D, Kourousis C, Koutras A, Papadimitriou C, Bamias C, Kosmidis P, Dimopoulos MA (2004) Docetaxel and cisplatin with granulocyte colonystimulating factor (G-CSF) versus MVAC with G-CSF in advanced urothelial carcinoma: a multicenter, randomized, phase III study from the Hellenic Cooperative Oncology Group. J Clin Oncol 22(2): 220-228.

Bellmunt J, Guillem V, Paz-Ares L, Gonzalez-Larriba JL, Carles J, Batiste-Alentorn E, Saenz A, Lopez-Brea M, Font A, Nogue M, Bastus R, Climent MA, de la Cruz JJ, Albanell J, Banus JM, Gallardo E, Diaz-Rubio E, Cortes-Funes H, Baselga J (2000) Phase I-II study of paclitaxel, cisplatin, and gemcitabine in advanced transitional-cell carcinoma of the urothelium. Spanish Oncology Genitourinary Group. J Clin Oncol 18(18): 3247-3255.

Bellmunt J, von der Maase H, Mead GM, Skoneczna I, De Santis M, Daugaard G, Boehle A, Chevreau C, Paz-Ares L, Laufman LR, Winquist E, Raghavan D, Marreaud S, Collette S, Sylvester R, de Wit R (2012) Randomized phase III study comparing paclitaxel/cisplatin/ gemcitabine and gemcitabine/cisplatin in patients with locally advanced or metastatic urothelial cancer without prior systemic therapy: EORTC Intergroup Study 30987. J Clin Oncol 30(10): 1107-1113.

Christoph DC, Asuncion BR, Mascaux C, Tran C, Lu X, Wynes MW, Gauler TC, Wohlschlaeger J, Theegarten D, Neumann V, Hepp R, Welter S, Stamatis G, Tannapfel A, Schuler M, Eberhardt WE, Hirsch FR (2012) Folylpoly-glutamate synthetase expression is associated with tumor response and outcome from pemetrexed-based chemotherapy in malignant pleural mesothelioma. J Thorac Oncol 7(9): 1440-1448.

De Lena M, Lorusso V, Iacobellis U, Marzullo F, Maiello E, Cramarossa A (1984) Cis-diamminedichloroplatinum activity in bidimensionally measurable metastatic lesions of bladder carcinoma. Tumori 70(1): 85-88.

Dimopoulos MA, Bakoyannis C, Georgoulias V, Papadimitriou C, Moulopoulos LA, Deliveliotis C, Karayannis A, Varkarakis I, Aravantinos G, Zervas A, Pantazopoulos D, Fountzilas G, Bamias A, Kyriakakis Z, Anagnostopoulos A, Giannopoulos A, Kosmidis P (1999) Docetaxel and cisplatin combination chemotherapy in advanced carcinoma of the urothelium: a multicenter phase II study of the Hellenic Cooperative Oncology Group. Ann Oncol 10(11): 1385-1388.

Dreicer R, Li H, Cooney MM, Wilding G, Roth BJ. Eastern Cooperative Oncology G (2008) Phase 2 trial of pemetrexed disodium and gemcitabine in advanced urothelial cancer (E4802): a trial of the Eastern Cooperative Oncology Group. Cancer 112(12): 2671-2675.

Dreicer R, Manola J, Roth BJ, See WA, Kuross S, Edelman MJ, Hudes GR, Wilding G (2004) Phase III trial of methotrexate, vinblastine, doxorubicin, and cisplatin versus carboplatin and paclitaxel in patients with advanced carcinoma of the urothelium. Cancer 100(8): 1639-1645.

Galsky MD, Mironov S, Iasonos A, Scattergood J, Boyle MG, Bajorin DF (2007) Phase II trial of pemetrexed as second-line therapy in patients with metastatic urothelial carcinoma. Invest New Drugs 25(3): 265-270.

Herr HW (1980) Cis-diamminedichloride platinum II in the treatment of advanced bladder cancer. J Urol 123(6): 853-855.

Jemal A, Bray F, Center MM, Ferlay J, Ward E, Forman D (2011) Global cancer statistics. CA Cancer J Clin 61(2): 69-90.

Liu Y, Yin TJ, Zhou R, Zhou S, Fan L, Zhang RG (2013) Expression of thymidylate synthase predicts clinical outcomes of pemetrexed-containing chemotherapy for non-small-cell lung cancer: a systemic review and metaanalysis. Cancer Chemother Pharmacol 72(5): 1125-1132.

Martin AL, Bellmunt J, maroto JP, Gallardo E, Brea ML, Perez-Gracia JL, Castellano DE, Valverde CM, Bezares S, Calvo E, Pza-Ares L (2013) Phase I/II study of biweekly pemetrexed plus cisplatin in patients with locally advanced, nonresectable or metastatic urothelial cancer: Safety and efficacy results from phase II. J Clin Oncol 31(suppl): abstr 4550 .

Paz-Ares L, Bezares S, Tabernero JM, Castellanos D, Cortes-Funes H (2003a) Review of a promising new agent-pemetrexed disodium. Cancer 97(8 Suppl): 2056-2063.
Paz-Ares L, Bezares S, Tabernero JM, Castellanos D, Cortes-Funes H (2003b) Review of a promising new agent-pmetrexed disodium. Cancer 97(S8): 2056-2063.

Rossof AH, Talley RW, Stephens R, Thigpen T, Samson MK, Groppe Jr C, Eyre HJ, Fisher R (1979) Phase II evaluation of cisdichlorodiammineplatinum(II) in advanced malignancies of the genitourinary and gynecologic organs: a Southwest Oncology Group Study. Cancer Treat Rep 63(9-10): 1557-1564.

Scagliotti GV, Parikh P, von Pawel J, Biesma B, Vansteenkiste J, Manegold C, Serwatowski P, Gatzemeier U, Digumarti R, Zukin M, Lee JS, Mellemgaard A, Park K, Patil S, Rolski J, Goksel T, de Marinis F, Simms L, Sugarman KP, Gandara D (2008) Phase III study comparing cisplatin plus gemcitabine with cisplatin plus pemetrexed in chemotherapy-naive patients with advanced-stage non-small-cell lung cancer. J Clin Oncol 26(21): 3543-3551.

Schemper M, Smith TL (1996) A note on quantifying follow-up in studies of failure time. Control Clin Trials 17(4): 343-346.

Schultz RM, Patel VF, Worzalla JF, Shih C (1999) Role of thymidylate synthase in the antitumor activity of the multitargeted antifolate, LY231514. Anticancer Res 19(1A): 437-443.

Shih C, Habeck LL, Mendelsohn LG, Chen VJ, Schultz RM (1998) Multiple folate enzyme inhibition: mechanism of a novel pyrrolopyrimidine-based antifolate LY231514 (MTA). Adv Enzyme Regul 38: 135-152.

Smit EF, Socinski MA, Mullaney BP, Myrand SP, Scagliotti GV, Lorigan P, Reck M, Ciuleanu T, von Pawel J, Karaseva NA, Szczesna A, Ohannesian D, Powell E, Hozak RR, Hong S, Guba SC, Thatcher N (2012) Biomarker analysis in a phase III study of pemetrexed-carboplatin versus etoposide-carboplatin in chemonaive patients with extensive-stage smallcell lung cancer. Ann Oncol 23(7): 1723-1729.

Sternberg CN, de Mulder P, Schornagel JH, Theodore C, Fossa SD, van Oosterom AT, Witjes JA, Spina M, van Groeningen CJ, Duclos B, Roberts JT, de Balincourt C, Collette L. Group EG-UC (2006) Seven year update of an EORTC phase III trial of high-dose intensity M-VAC chemotherapy and G-CSF versus classic M-VAC in advanced urothelial tract tumours. Eur J Cancer 42(1): 50-54.

Sternberg CN, de Mulder PHM, Schornagel JH, Theodore C, Fossa SD, van Oosterom AT, Witjes F, Spina M, van Groeningen CJ, de Balincourt C, Collette L (2001) Randomized phase III trial of high-dose-intensity methotrexate, vinblastine, doxorubicin, and cisplatin (MVAC) chemotherapy and recombinant human granulocyte colonystimulating factor versus classic MVAC in advanced urothelial tract tumors: European Organization for Research and Treatment of Cancer protocol No. 30924. J Clin Oncol 19(10): 2638-2646.

Sweeney CJ, Roth BJ, Kabbinavar FF, Vaughn DJ, Arning M, Curiel RE, Obasaju CK, Wang Y, Nicol SJ, Kaufman DS (2006) Phase II study of pemetrexed for second-line treatment of transitional cell cancer of the urothelium. J Clin Oncol 24(21): 3451-3457.

Takezawa K, Okamoto I, Okamoto W, Takeda M, Sakai K, Tsukioka S, Kuwata K, Yamaguchi H, Nishio K, Nakagawa K (2011) Thymidylate synthase as a determinant of pemetrexed sensitivity in non-small cell lung cancer. Br J Cancer 104(10): 1594-1601.

Taylor EC, Kuhnt D, Shih C, Rinzel SM, Grindey GB, Barredo J, Jannatipour M, Moran RG (1992) A dideazatetrahydrofolate analogue lacking a chiral center at C-6, N-[4-[2-(2-amino-3,4-dihydro4-oxo-7H-pyrrolo[2,3-d]pyrimidin-5- yl)ethyl]benzoyl]-L-glutamic acid, is an inhibitor of thymidylate synthase. J Med Chem 35(23): $4450-4454$.

Vaughn DJ, Malkowicz SB, Zoltick B, Mick R, Ramchandani P, Holroyde C, Armstead B, Fox K, Wein A (1998) Paclitaxel plus carboplatin in advanced carcinoma of the urothelium: an active and tolerable outpatient regimen. $J$ Clin Oncol 16(1): 255-260.

Vogelzang NJ, Rusthoven JJ, Symanowski J, Denham C, Kaukel E, Ruffie P, Gatzemeier U, Boyer M, Emri S, Manegold C, Niyikiza C, Paoletti P (2003) Phase III study of pemetrexed in combination with cisplatin versus cisplatin alone in patients with malignant pleural mesothelioma. J Clin Oncol 21(14): 2636-2644.

von der Maase H, Hansen SW, Roberts JT, Dogliotti L, Oliver T, Moore MJ, Bodrogi I, Albers P, Knuth A, Lippert CM, Kerbrat P, Sanchez Rovira P, Wersall P, Cleall SP, Roychowdhury DF, Tomlin I, Visseren-Grul CM, Conte PF (2000) Gemcitabine and cisplatin versus methotrexate, vinblastine, doxorubicin, and cisplatin in advanced or metastatic bladder cancer: results of a large, randomized, multinational, multicenter, phase III study. J Clin Oncol 18(17): 3068-3077. 
von der Maase H, Lehmann J, Gravis G, Joensuu H, Geertsen PF, Gough J, Chen G, Kania M (2006) A phase II trial of pemetrexed plus gemcitabine in locally advanced and/or metastatic transitional cell carcinoma of the urothelium. Ann Oncol 17(10): 1533-1538.
This work is published under the standard license to publish agreement. After 12 months the work will become freely available and the license terms will switch to a Creative Commons AttributionNonCommercial-Share Alike 3.0 Unported License. 